Keywords: animal welfare; biomarkers; cancer research; E $\mu$-myc; humane end points; lymphoma; mice; replacement; reduction; refinement (3Rs); temperature; tumour burden

\title{
Using body temperature, food and water consumption as biomarkers of disease progression in mice with E $\mu$-myc lymphoma
}

\author{
J E Hunter ${ }^{1}$, J Butterworth ${ }^{1}$, N D Perkins ${ }^{1}$, M Bateson ${ }^{2}$ and C A Richardson ${ }^{\star 2}$, \\ ${ }^{1}$ Institute for Cell and Molecular Biosciences, Medical School, Newcastle University, Framlington Place, Newcastle upon Tyne, NE2 \\ $4 H H, U K$ and ${ }^{2}$ Centre for Behaviour and Evolution/Institute of Neuroscience, Medical School, Newcastle University, Framlington \\ Place, Newcastle upon Tyne, NE2 4HH, UK
}

Background: Non-invasive biomarkers of disease progression in mice with cancer are lacking making it challenging to implement appropriate humane end points. We investigated whether body temperature, food and water consumption could be used to predict tumour burden.

Methods: Thirty-six male, wild-type C57BI/6 mice were implanted with subcutaneous RFID temperature sensors and inoculated with E $\mu$-myc tumours that infiltrate lymphoid tissue.

Results: Decrease in body temperature over the course of the study positively predicted post-mortem lymph node tumour burden $\left(R^{2}=0.68, F(1,22)=44.8, P<0.001\right)$. At experimental and humane end points, all mice that had a mean decrease in body temperature of $0.7^{\circ} \mathrm{C}$ or greater had lymph nodes heavier than $0.5 \mathrm{~g}(100 \%$ sensitivity), whereas a mean decrease in body temperature $<0.7^{\circ} \mathrm{C}$ always predicted lymph nodes lighter than $0.5 \mathrm{~g}(100 \%$ specificity). The mean decrease in food consumption in each cage also predicted mean post-mortem lymph node tumour burden at 3 weeks $\left(R^{2}=0.89, F(1,3)=23.2, P=0.017\right)$.

Conclusion: Temperature, food and water consumption were useful biomarkers of disease progression in mice with lymphoma and could potentially be used more widely to monitor mice with other forms of cancer.

Animals continue to be used in cancer research as in vivo studies to help elucidate mechanisms involved in the development/pathology of cancers and are used to improve diagnostic methods and treatment. A recent working party report concluded that studies involving animals remain essential in cancer research but that it is necessary to integrate the 3Rs (Replacement, Reduction and Refinement) into this work as the appropriate use of animals is a prerequisite to good science (Workman et al, 2010). The 3Rs proposed by William Russell and Rex Burch in 1959 refer to the replacement of animals used in research with non-sentient alternatives, the reduction of the number of animals used in research and the refinement of experimental and husbandry procedures to minimise pain and distress (Russell and Burch, 1959).

The application of appropriate and objective humane end points is essential when refining in vivo cancer research to minimise pain and/or distress. Humane end points refer to 'criteria that allow early termination of experiments before animals experience significant harm while still meeting the experimental objectives' (NC3Rs, 2013). One of the main obstacles to implementing humane end points is a general lack of biomarkers that can be used as specific indicators of disease progression (Franco et al, 2012), and this has been identified as a particular concern in in vivo cancer research (Workman et al, 2010). Although sometimes tumour burden and disease progression can be directly measured using callipers (e.g., subcutaneous tumours) in many other cancer studies (e.g., thoracic, peritoneal and lymphoreticular tumours), it cannot.

Imaging is frequently advocated as a method of tracking disease progression in animals with cancer but repeated anaesthesia is typically required, which may affect experimental outcomes and have a welfare cost (Workman et al, 2010; Wong et al, 2013).

*Correspondence: Dr CA Richardson; E-mail: Claire.Richardson@ncl.ac.uk

Received 25 September 2013; revised 9 December 2013; accepted 9 December 2013;

published online 9 January 2014

(C) 2014 Cancer Research UK. All rights reserved 0007 - 0920/14

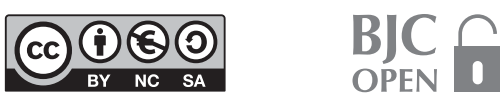


Furthermore, imaging is financially costly, requires specialist skills and equipment, and may not be carried out at a sufficient frequency to detect critical points in disease progression. The use of specific clinical signs as biomarkers has the advantage that they can be obtained quickly and non-invasively. Weight loss is the most frequently used clinical biomarker in disease studies, but reliance on changes in body weight as a single indicator of disease progression is problematic (Franco et al, 2012) particularly in cancer research due to the weight of the tumours.

The aim of this study was therefore to identify biomarkers of disease progression in mice with lymphoma. Rather than use animals specifically for this study, enhanced monitoring of wildtype mice implanted with $\mathrm{E} \mu-m y c$ tumours that were involved in an ongoing programme of work was carried out. Transgenic E $\mu$ $m y c$ mice are widely used to study haematological malignancies and are known to develop aggressive lymphoma (Harris et al, 1988). This strain is frequently crossed with other genetically altered mice (e.g. with altered anti-apoptotic factors, Bcl-xl, Mcl-1) to investigate the effects of different genes in vivo (Campbell et al, 2010; Kelly et al, 2011) and to test the efficacy of novel therapeutic agents (Ferrao et al, 2012; Wall et al, 2013). In order to minimise the heterogeneity and spontaneity of the tumours, primary tumour cells are frequently obtained from the lymphoid organs of $\mathrm{E} \mu-m y c$ animals, grown ex vivo and implanted into multiple syngeneic recipients. Mice implanted with $\mathrm{E} \mu-m y c$ tumours typically develop enlarged lymph nodes, spleens and thymus by $2-4$ weeks post implantation. However, there is often considerable variation in disease progression depending on the primary tumour implanted making it challenging to apply appropriate humane end points.

We hypothesised that body temperature might predict tumour burden in mice implanted with $\mathrm{E} \mu-m y c$ tumours. Temperature has been used as a surrogate marker of imminent death in many fields of in vivo research (Ray et al, 2010), and in cancer studies persistent hypothermia has been identified as a severe clinical sign necessitating immediate intervention (Workman et al, 2010). Thermoregulation in mice is known to be energetically expensive (Gaskill et al, 2013a), but there is a lack of detailed information on how body temperature changes in mice developing cancer. A secondary hypothesis was that directly measuring food and water would provide an earlier predictor of disease onset at the cage level compared with mean body weight.

\section{MATERIALS AND METHODS}

All procedures were carried out under project and personal licences approved by the Secretary of State for the Home Office, under the United Kingdom's 1986 Animal (Scientific Procedures) Act and approved by Newcastle University's Animal Welfare and Ethical Review Body. Thirty-six wild-type male C57BL/6 mice obtained from Charles River Laboratories (Ramsgate, Kent, UK) were studied. Animals were free from all major pathogens and drug and test naive. Mice were housed in groups of 6 per cage in individually ventilated cages (IVCs) $\left(580 \mathrm{~cm}^{3}\right.$, Maxiseal 580 , Arrowmight, Hereford, UK) with 20 air changes per hour. Aspen woodchips (Tapvei, Datesand, Manchester, UK) and nesting material (1 nestlet/3 mice (FDA Nestlets, Datesand, Manchester, UK)) were used as bedding. Tap water and commercial pelleted diet (R\&M no.3, SDS limited, Whitham, UK) were available ad libitum. The room was maintained at $23^{\circ} \mathrm{C} \pm 1{ }^{\circ} \mathrm{C}$ on a light cycle ( $12 \mathrm{~h} / 12 \mathrm{~h}$, lights on at 0700 hours).

Transponder implantation was carried out 3 days before tumour implantation by briefly anaesthetising mice with isoflurane then subcutaneously injecting a transponder $(2.2 \times 14 \mathrm{~mm}$; $0.12 \mathrm{~g}$; IPTT300, PLEXX BV, ELST, The Netherlands) into each animal. An automated reader system (Vertical Smart Probe (VSP-7005)/DAS8001 Data Acquisition System/DAS-7001 wireless interface (PLEXX
BV, ELST, The Netherlands)) was used to read temperatures. Temperatures were taken 5-7 days/week between 0800 and 1100 hours by sequentially taking cages off the IVC rack, removing cage lids then placing readers directly adjacent to the cage (Figure 1) for $\sim 5 \mathrm{~min}$. Readings were obtained (animal identification/time/ temperature) each time a mouse was within reading range $(5-8 \mathrm{~cm})$ of the reader. Values greater than $40^{\circ} \mathrm{C}$ or less than $33^{\circ} \mathrm{C}$ and values that changed more than $3^{\circ} \mathrm{C}$ within any $30 \mathrm{~s}$ period were considered as outliers and excluded. Daily temperature for each animal was the first valid temperature recorded. The food and water consumption of each cage was also measured daily by weighing the food hopper/water bottle and subtracting the measured weight of food/water from the amount measured the previous day. Mice were weighed following temperature readings.

Mice were randomly allocated to cage and tumour groups. Animals were 8 weeks old with a mean body weight of $22.7 \mathrm{~g}$ (s.e.m. $=0.25 \mathrm{~g}$ ) when they were implanted with $\mathrm{E} \mu-m y c$ tumour cells. Cells had been collected from spontaneous lymphoid tumours of $\mathrm{E} \mu-m y c$ transgenic animals, frozen and cryogenically stored as previously described (Mason et al, 2008). Tumour cells were then re-implanted into other animals by intravenous injections via the lateral tail vein of $1 \times 10^{6}$ viable cells in a phosphate-buffered saline vehicle. Three primary tumours were used and each was injected into 12 mice (1 primary tumour/2 cages). Clinical signs were recorded daily for each individual mouse, using clinical observation sheets (Hawkins, 2002). Mice were killed at pre-determined experimental end points 2, 3, 4 and 5 weeks post administration ( 3 mice killed/primary tumour at each experimental end point) unless pre-defined severity limits were approached or met. Mice were killed earlier than their planned experimental end point if 2 experienced researchers (JEH, CAR) considered disease severity to be moderate based on clinical
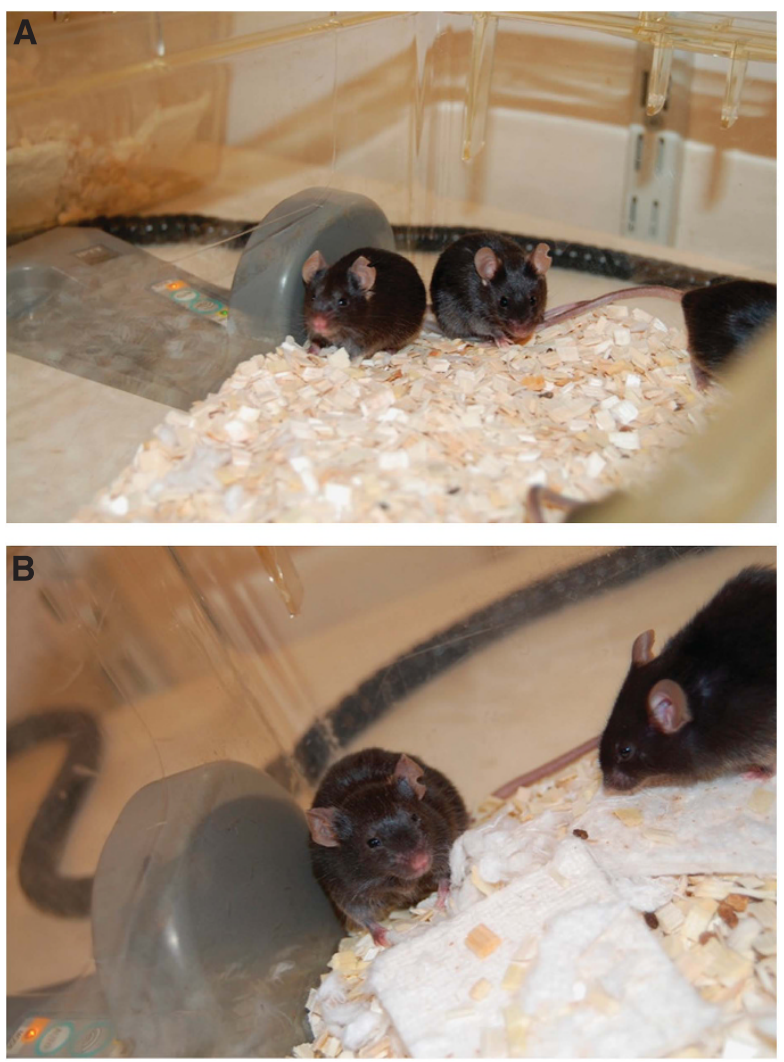

Figure 1. Position of RFID transponder reader next to homecage. (A) Mice not exhibiting clinical signs of lymphoma (primary tumour 1, experimental day 20). (B) Mice with clinical signs of lymphoma 1 day before humane killing (primary tumour 3, experimental day 20). 
impression or if they exhibited any of the clinical signs listed by Workman et al (2010) as necessitating immediate intervention. Mice were killed by an overdose of isoflurane, and organs were subsequently collected and weighed. As lymphoma causes an enlargement of lymphoid organs, tumour burden was measured as the gross weight of the pooled lymph nodes (cervical, brachial, inguinal and mesenteric), thymus and spleen.

All statistical analyses were conducted using IBM SPSS 19 software (IBM SPSS Inc, Armonk, NY, USA). The experimental unit for all analyses was mouse with the exception of food/water consumption where the cage was the experimental unit (individual food and water consumption could not be measured in standard individually ventilated cages). Because of the variation in baseline values, changes in parameters over the course of the study were studied (e.g., change from baseline values in body temperature, body weight and food/water consumption). Change in body temperature over the course of the study was calculated for each mouse as the difference between mean temperature over the 3 days before killing and the 3 days following tumour implantation. Proportional weight loss for each individual was calculated as the difference between final and maximum body weight compared with maximum body weight (e.g., a mouse with a peak body weight of $30 \mathrm{~g}$ over the course of the study who weighed $28 \mathrm{~g}$ at the end point would be considered to have a proportional weight loss of $6.7 \%)$. The comparison was made with maximum body weight (rather than baseline body weight) as growing mice were studied.

Simple linear regression was used to test whether clinical signs (e.g., change in body temperature, proportional weight loss) predicted tumour burden/weight in the lymphoid organs (pooled lymph nodes, thymus and spleen) of each mouse. Fisher's exact test was used to test for association between clinical parameters (change in temperature and weight loss) and tumour burden/ weight of pooled lymph nodes. Differences in post-mortem organ weight were evaluated using a multivariate general linear model with time point and tumour as between-subject factors and pooled lymph node, thymus and spleen weights as within-subject factors. One sample $t$-tests with a Bonferonni correction were used to test for an overall change in food/water consumption. Simple linear regression was also used to test whether mean decrease in food and water consumption in each cage predicted mean tumour burden/weight of the lymphoid organs of the animals in the cage at 3 weeks. Proportional decrease in food/ water consumption was calculated as change in mean consumption from experimental week 3 to 1 compared with mean consumption at experimental week 1 (e.g., a cage of mice that consumed an average of $3 \mathrm{~g}$ per day over experimental week 1 and $2 \mathrm{~g}$ per day over experimental week 3 would have a decrease in food consumption of $33 \%$.). Significance for all statistical tests was established at $P<0.05$, data are presented as mean ( \pm s.e.m.).

\section{RESULTS}

One mouse implanted with tumour 2 was killed on experimental day 0 following an unsuccessful intravenous injection. Clinical signs observed when humane end points were implemented included ruffled coat, enlarged cervical lymph nodes and dull demeanour (Figure 1B). With the exception of enlarged lymph nodes, none of the mice exhibited clinical signs listed by Workman et al (2010) as necessitating immediate intervention. On the basis of clinical impression, primary tumour 1 was the least aggressive; none of the mice implanted with tumour 1 were killed earlier than pre-determined experimental end points. Six mice from each of experimental groups implanted with primary tumours 2 and 3 were killed earlier than pre-determined experimental end points of 4 and 5 weeks (mice killed days 21-23 and classified as being killed at the 3 week time point).

Six of the RFID transponders failed over the first 7 experimental days (three from tumour group 1, two from tumour group 2, one from tumour group 3). Data from the mice affected by the faulty transponders are included in food/water consumption and bodyweight analysis but not body temperature analysis (Table 1). Less than $1 \%$ of temperature readings were classed as outliers and excluded based on pre-determined criteria.

Mean change in body temperature over the course of the study predicted tumour burden in the lymph nodes $\left(R^{2}=0.68\right.$, $\mathrm{F}(1,22)=44.8, P<0.001)$, thymus $\left(R^{2}=0.51, \mathrm{~F}(1,22)=21.6\right.$, $P<0.001)$ and spleen $\left(R^{2}=0.31, \mathrm{~F}(1,22)=9.5, P=0.006\right)$ at post-mortem (Figure $2 \mathrm{~A}-\mathrm{C}$ ). Proportional change in body weight also predicted tumour burden in the lymph nodes $\left(R^{2}=0.31\right.$, $\mathrm{F}(1,22)=9.2, P=0.006$ ) (Figure $2 \mathrm{D}$ ) but not the thymus or the spleen (Figure $2 \mathrm{E}$ and $\mathrm{F}$ ).

The data were examined post-hoc to determine whether any clinical criteria reliably predicted disease progression. At experimental and humane end points, a criterion of a mean decrease in body temperature of $0.7^{\circ} \mathrm{C}$ or greater would have always detected mice with lymph nodes heavier than or equal to $0.5 \mathrm{~g}(100 \%$ sensitivity) (Table 2). Similarly a criterion of a mean decrease in body temperature $<0.7^{\circ} \mathrm{C}$ would have always detected lymph nodes lighter than 0.5 grams ( $100 \%$ specificity) (Table 2$)$. In contrast, although a weight loss criterion of $5 \%$ or greater would have $100 \%$ specificity for detecting lymph nodes heavier than $0.5 \mathrm{~g}$, sensitivity would decrease to $60 \%$ and $40 \%$ of mice with lymph nodes heavier than $0.5 \mathrm{~g}$ would not have been detected (Table 2). Associations between the temperature criterion of $-0.7^{\circ} \mathrm{C}$ and the weight loss criterion of $5 \%$ with thymus and spleen tumour burden are summarised in Table 2.

Post-mortem findings confirmed that tumour 1 was the least aggressive primary tumour and there was an overall effect of both time $(\mathrm{F}(3,21)=3.1, P=0.047)$ and primary tumour $(\mathrm{F}(6,44)=4.3$, $P=0.002)$ on organ weight (lymph nodes, thymus and spleen) (Figure $3 \mathrm{~A}-\mathrm{C}$ ). In the two cages of mice implanted with primary tumour 1 , mean body weight of the animals increased over the 21 experimental days, and there was little daily variation in food or water consumption (Figure 3D). In contrast, in cages with mice implanted with primary tumours 2 and 3 , mean body weight fell over the last 4-5 experimental days, and both food and water consumption began to decline from experimental day 12 (Figure $3 \mathrm{E}$ and $\mathrm{F}$ ). The only clinical observation recorded over the first 12 days of the study was fighting. Clinical signs of sickness

\begin{tabular}{|c|c|c|c|c|}
\hline Time & Food/water consumption & Body weight & Body temperature & Organ weight \\
\hline 2 weeks & Tumours 1-3: $n=2$ & $\begin{array}{l}\text { Tumour 1: } n=12 \\
\text { Tumour 2: } n=11 \\
\text { Tumour 3: } n=12\end{array}$ & $\begin{array}{l}\text { Tumour 1: } n=9 \\
\text { Tumour 2: } n=9 \\
\text { Tumour 3: } n=11\end{array}$ & Tumours 1-3: $n=3$ \\
\hline 3 weeks & Tumours 1-3: $n=2$ & $\begin{array}{l}\text { Tumour 1: } n=9 \\
\text { Tumour 2: } n=8 \\
\text { Tumour 3: } n=9\end{array}$ & $\begin{array}{l}\text { Tumour 1: } n=6 \\
\text { Tumour 2: } n=6 \\
\text { Tumour 3: } n=8\end{array}$ & $\begin{array}{l}\text { Tumour 1: } n=3 \\
\text { Tumour 2: } n=8 \\
\text { Tumour 3: } n=9\end{array}$ \\
\hline
\end{tabular}



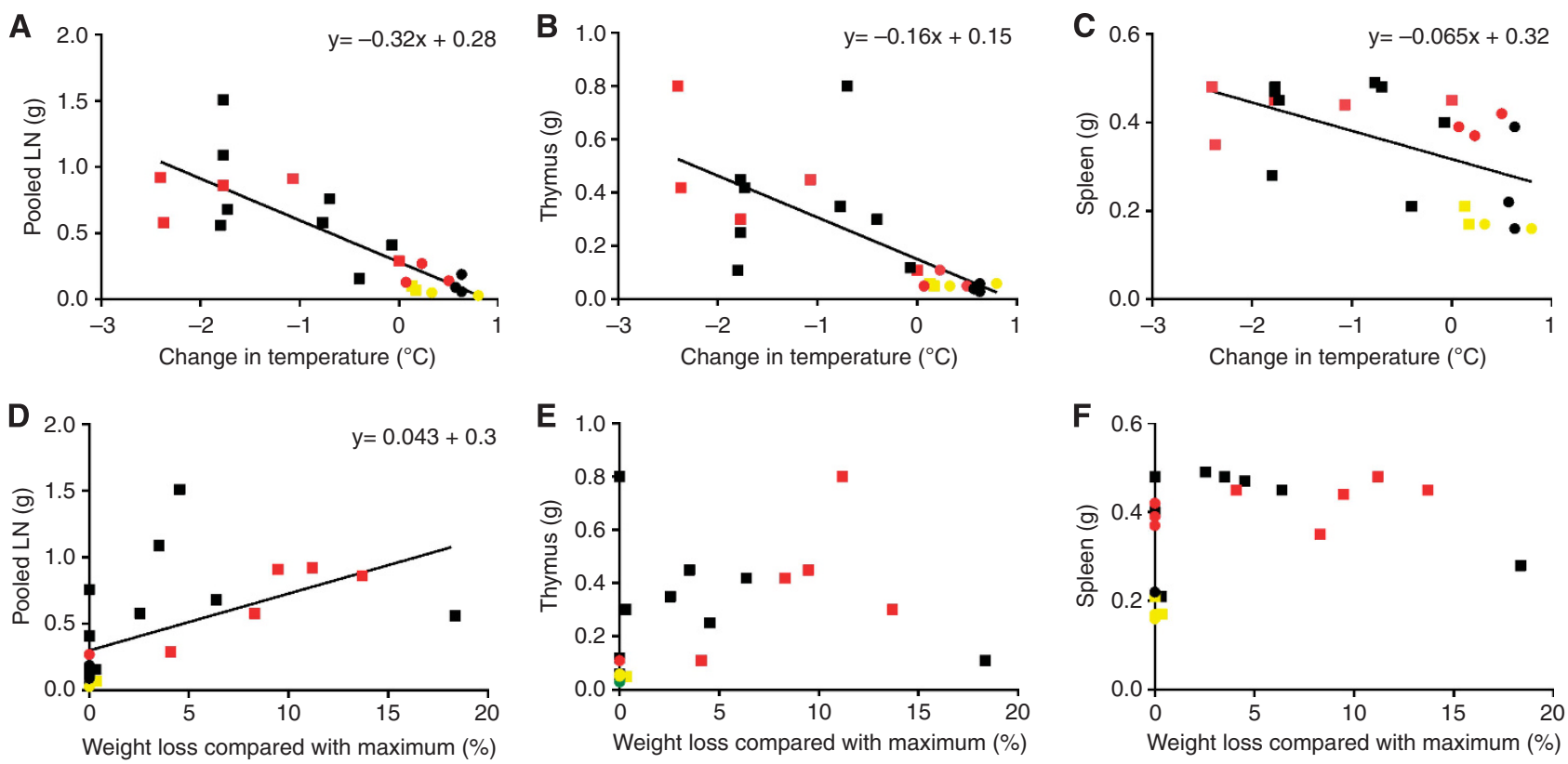

Figure 2. Relationships between clinical biomarkers and tumour burden. Circles indicate 2 week endpoint, squares indicate 3 week endpoint. Tumour 1 in yellow, tumour 2 in red and tumour 3 in black. (A-C) Scatter plots to show relationships between change in body temperature and total weight of lymph nodes (cervical, brachial, inguinal, mesenteric), thymus and spleen. (D-F) Scatter plots to show relationships between change in body weight and total post-mortem weight of lymphoid organs.

\begin{tabular}{|c|c|c|c|c|}
\hline & \multicolumn{2}{|c|}{$\begin{array}{l}\text { Mean change in body } \\
\text { temperature } \geqslant 0.7^{\circ} \mathrm{C}\end{array}$} & \multicolumn{2}{|c|}{$\begin{array}{l}\text { Change from maximum } \\
\text { body weight } \geqslant 5 \%\end{array}$} \\
\hline & $\begin{array}{l}\text { Negative } \\
\text { (\%) }\end{array}$ & $\begin{array}{l}\text { Positive } \\
\text { (\%) }\end{array}$ & $\begin{array}{l}\text { Negative } \\
\text { (\%) }\end{array}$ & $\begin{array}{l}\text { Positive } \\
\text { (\%) }\end{array}$ \\
\hline \multicolumn{5}{|c|}{ Pooled lymph node weight (g) } \\
\hline $\begin{array}{l}<0.5 \mathrm{~g} \\
\geqslant 0.5 \mathrm{~g} \\
P \text { value }\end{array}$ & $\begin{array}{l}13(100 \%) \\
0(0 \%)\end{array}$ & $\begin{array}{c}0(0 \%) \\
10(100 \%) \\
<0.0001\end{array}$ & $\begin{array}{c}13(100 \%) \\
4(40 \%)\end{array}$ & $\begin{array}{l}0(0 \%) \\
6(60 \%) \\
0.0021\end{array}$ \\
\hline \multicolumn{5}{|c|}{ Thymus weight (g) } \\
\hline $\begin{array}{l}<0.2 \mathrm{~g} \\
\geqslant 0.2 \mathrm{~g} \\
P \text {-value }\end{array}$ & $\begin{array}{r}12(92 \%) \\
1(10 \%)\end{array}$ & $\begin{array}{l}1(8 \%) \\
9(90 \%) \\
0.0001\end{array}$ & $\begin{array}{r}12(92 \%) \\
5(50 \%)\end{array}$ & $\begin{array}{c}1(8 \%) \\
5(50 \%) \\
\text { NS }\end{array}$ \\
\hline \multicolumn{5}{|c|}{ Spleen weight (g) } \\
\hline $\begin{array}{l}<0.3 \mathrm{~g} \\
\geqslant 0.3 \mathrm{~g} \\
P \text {-value }\end{array}$ & $\begin{array}{l}7(88 \%) \\
6(40 \%)\end{array}$ & $\begin{array}{c}1(12 \%) \\
9(60 \%) \\
\text { NS }\end{array}$ & $\begin{array}{r}7 \text { (88\%) } \\
10(67 \%)\end{array}$ & $\begin{array}{c}1(12 \%) \\
5(33 \%) \\
\text { NS }\end{array}$ \\
\hline
\end{tabular}

for mice implanted with tumours 2 and 3 were noted from experimental day 12 and are summarised in Table 3. Some of the clinical signs summarised in Table 3 were also noted in mice implanted with tumour 1 from experimental day 17. An increase in burrowing behaviour was noted from experimental day 12 where mice were observed to move around in their homecages with their noses emerged in dirty bedding (Figure 4).

Over the first 2 weeks of the study, mean body temperature in mice implanted with all 3 primary tumours was within $0.5^{\circ} \mathrm{C}$ of $36^{\circ} \mathrm{C}$ (Figure 3G-I). The mean body temperature of mice implanted with primary tumours 2 and 3 decreased between experimental weeks 2 and 3 (Figure $3 \mathrm{H}$ and $\mathrm{I}$ ).

Between experimental weeks 1 and 3 , there was an overall decrease in both food consumption $(\mathrm{t}(4)=9.6, P=0.007)$ and water consumption $(\mathrm{t}(4)=6.9, P=0.0024)$. At the cage level, proportional decrease in food consumption (week 3 compared with week 1) predicted mean tumour burden in the lymph nodes $\left(R^{2}=0.89, \quad \mathrm{~F}(1,3)=23.2, \quad P=0.017\right)$ and spleen $\left(R^{2}=0.90\right.$, $\mathrm{F}(1,3)=27.1, P=0.014$ ) but not in the thymus (Figure $5 \mathrm{~A}-\mathrm{C}$ ). The proportional decrease in water consumption predicted tumour burden in the thymus $\left(R^{2}=0.83, \mathrm{~F}(1,3)=14.7, P=0.31\right)$ but not in the lymph nodes or spleen (Figure 5D-F).

\section{DISCUSSION}

In this study, enhanced clinical monitoring of mice implanted with $\mathrm{E} \mu-m y c$ tumours elucidated stages of disease progression. The criterion of a mean decrease in body temperature of $0.7^{\circ} \mathrm{C}$ was a sensitive and specific indicator of tumour burden in lymphoid organs. As pain and distress are more likely to occur with greater tumour burdens in mice with cancer (Workman et al, 2010), humanely killing animals when tumour burden is as required for experimental outcomes is likely to refine in vivo cancer studies. Humanely killing animals at a uniform stage in disease progression can also minimise variation in post-mortem findings and reduce the overall number of animals required in in vivo cancer research.

Our work provides further evidence to support how reliance on weight loss as a biomarker of disease progression for mice with lymphoma may be problematic (Paster et al, 2009). Mean body weight did not begin to decrease until disease progression was relatively advanced and several animals with large tumours did not lose weight during the study.

In contrast to body weight, changes in body temperature did predict tumour burden in the lymphoid organs. One potential disadvantage of temperature as a biomarker of disease progression 


\section{Post-mortem \\ organ weights}

A

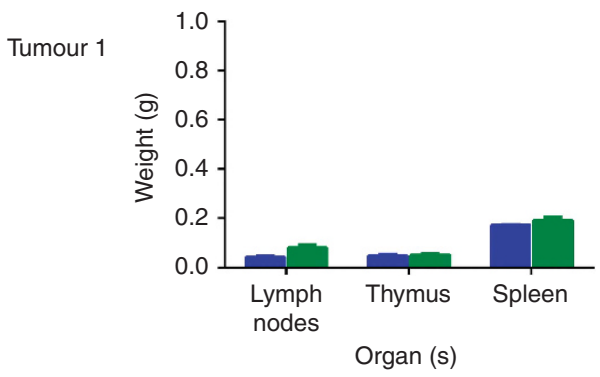

B

Tumour 2

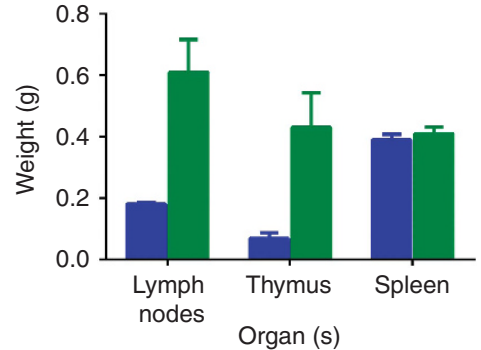

C

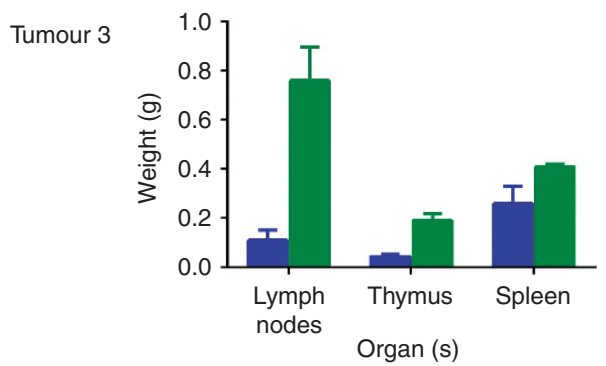

Body weight and food/water consumption

D

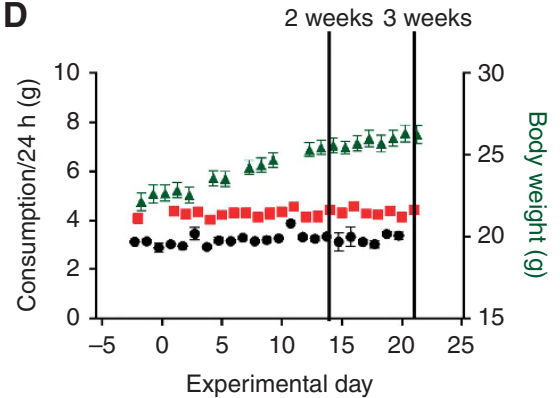

E

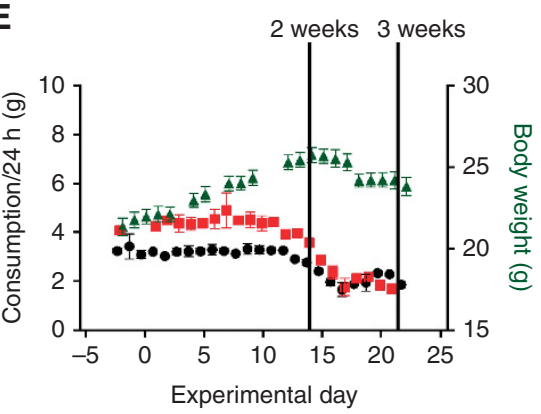

F

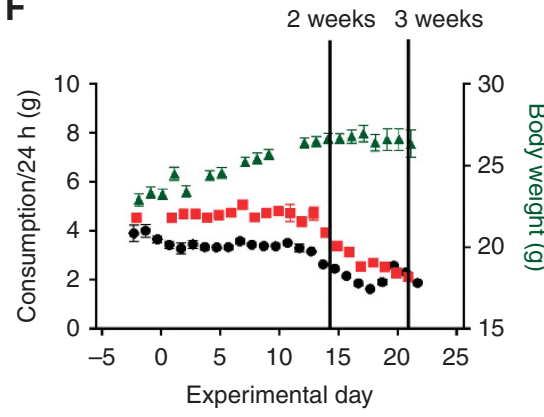

Body temperature

\section{G}

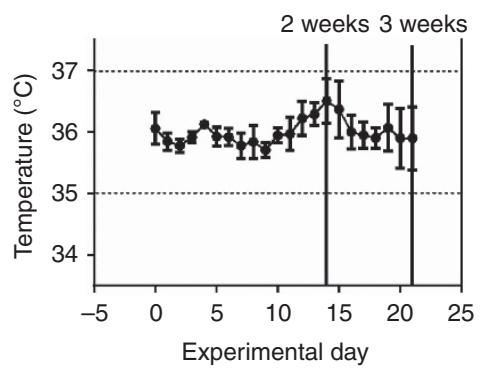

H

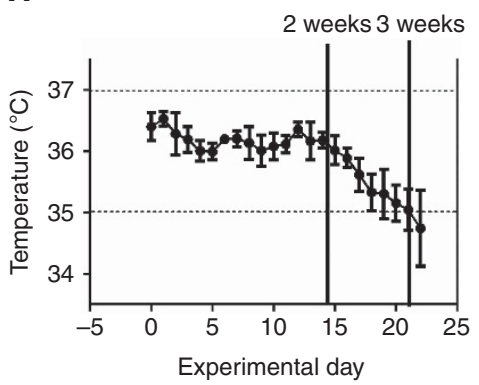

I

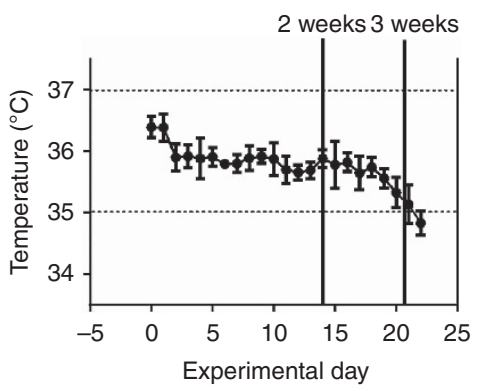

Figure 3. Tumour burden and changes in clinical biomarkers with disease progression. (A-C) Organ weights at post-mortem classified by primary tumour implanted (mean \pm s.e.m.). Two week endpoints in blue, 3 week endpoints in green. (D-F) Changes in food/water consumption and body weight following tumour implantation on experimental day 0 . Data plotted as mean \pm s.e.m. (mean body weight calculated from individual values; mean food/water consumption calculated from cage values). Body weight is in green, water consumption is in red and food consumption is in black. (G-I) Change in temperature following tumour implantation plotted as 3-day moving averages (mean $+/-$ s.e.m.).

Table 3. Summary table of clinical observations noted from experimental day 12 to end points

\begin{tabular}{|l|l|}
\hline $\begin{array}{l}\text { Type of clinical } \\
\text { observation }\end{array}$ & Terms used to describe clinical observations \\
\hline Change in coat & Dull, starey, ruffled, decreased grooming \\
\hline Demeanour & Dull \\
\hline Social interactions & Socially isolated, huddled \\
\hline Posture & Hunched, ears tilted back from baseline position \\
\hline Body systems & Pale, increased respiratory rate, sunken eyes \\
\hline
\end{tabular}

is the natural variability in body temperature, influenced by a large number of factors, including time of day, activity and activation of the sympathetic nervous system (Van Bogaert et al, 2006). When studying temperature in relation to disease progression it is therefore important to be consistent in the way that temperature is taken. To minimise the effects of time of day and stress induced hyperthermia (Bouwknecht and Olivier, 2007), in this study mean changes in the temperature of socially housed animals in their homecage were studied and temperature was always measured in the morning typically at the transition from sleeping to waking when the lid was removed from each cage. Because of nonpathological variation in temperature and occasional outlier readings, the decision to implement a humane end point should not be made solely based on a single reading but mean changes in body temperature should be considered alongside other clinical markers (e.g., changes in appearance of the animals' coat, demeanour, social interactions and posture). Clinical criteria that have been identified as relevant in mice with other types of lymphoma include body condition scores, general appearance (particularly coat condition) and natural behaviours (e.g., decrease in activity) (Paster et al, 2009) as well as decreased rearing, exploration and grooming (van Loo et al, 1997). In rodents with other cancers, relevant clinical indicators include hunching and vocalisation in mice with pancreatic cancer (Lindsay et al, 2005) and hunching, vocalisation and starey coats in rats with bladder 
cancer (Roughan et al, 2004). The further identification and dissemination of relevant clinical signs and biomarkers in mice with cancer should be encouraged (Kilkenny et al, 2010; Workman et al, 2010).

The criteria of $0.7^{\circ} \mathrm{C}$ decrease in body temperature and $5 \%$ weight loss were determined post-hoc and further studies are required to assess the predictive validity of these values. Similarly further work is needed to determine the efficacy of other

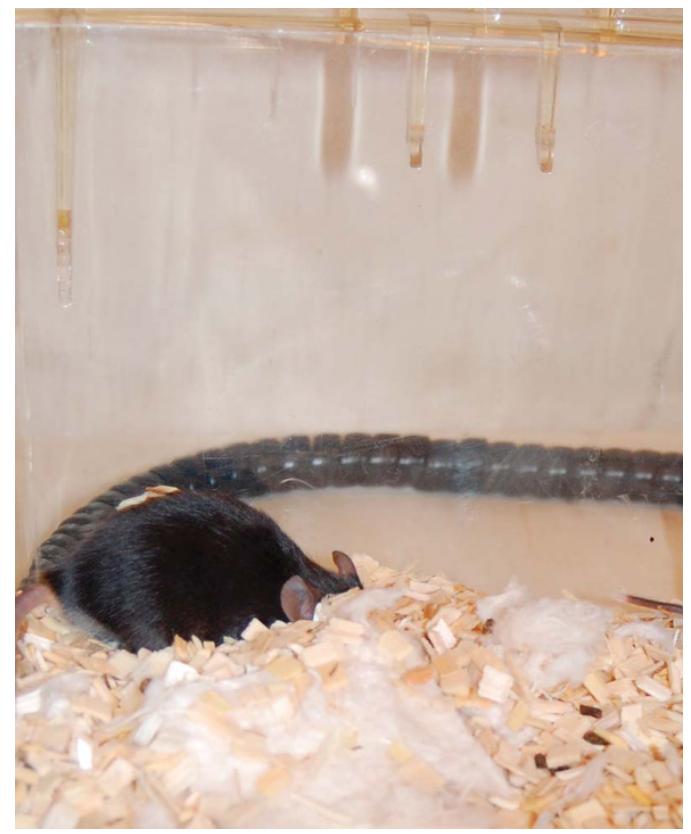

Figure 4. Mouse exhibiting burrowing behaviour, moving forwards in the cage with his nose immersed in dirty bedding. Picture taken on experimental day 15 . non-invasive methods of measuring body temperature including thermography cameras (Edgar et al, 2013; Gaskill et al, 2013a) and non-contact infrared thermometers (Warn et al, 2003) for monitoring mice with cancer.

Even if temperature is not monitored and used as a biomarker of tumour growth in mice with $\mathrm{E} \mu-m y c$ tumours, researchers should be aware that, as lymphoma develops, mice may be less able to thermoregulate. Recent studies have demonstrated that cold stress can have a negative impact on the welfare of healthy laboratory mice (Gaskill et al, 2011) as well as being a source of significant experimental variability in mice with cancer (Kokolus et al, 2013). Mice with $\mathrm{E} \mu-m y c$ tumours should therefore be housed with sufficient species-appropriate, naturalistic nesting material to allow the animals to carry out behavioural thermoregulation (Hess et al, 2008; Gaskill et al, 2012, 2013b). Similarly, more consideration/investigation should be given to the most appropriate housing temperature for in vivo cancer studies.

At the cage level, food and water consumption was early indicator of disease onset as mean food/water consumption started to fall several days earlier than body weight or temperature. Food and water consumption has also been shown to decrease in socially housed mice with other cancers such as subcutaneous prostate cancer xenografts (Jacobsen et al, 2013). Measuring food/water consumption by cage requires no specialised skills or equipment and can be useful when animals are housed by the experimental group and when disease progression is similar between animals. Although it is not possible to use food/water consumption as the basis for determining individual end points in mice housed socially in individually ventilated cages, by quickly detecting the onset of clinical signs refinements such as warmth or soaked diet can be introduced to cages when most needed. When mice with lymphoma are individually housed food and water consumption also decreases with tumour growth (van Loo et al, 1997) and could therefore be used to refine individual end points.

Provided that body temperature is taken and interpreted carefully, this study indicates that it can be a useful biomarker of
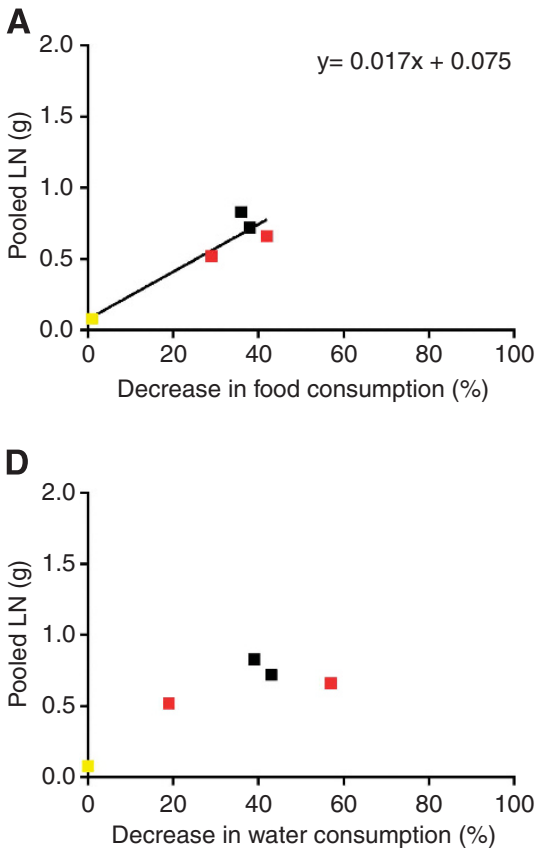
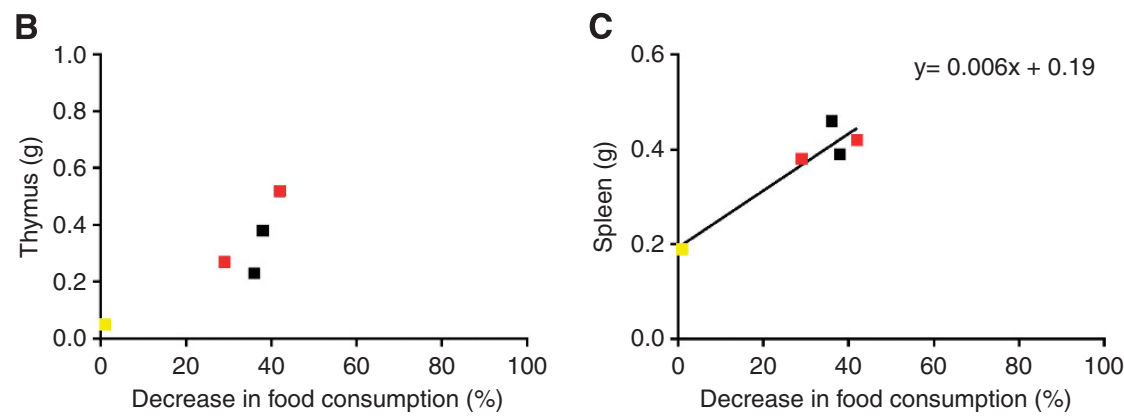

E

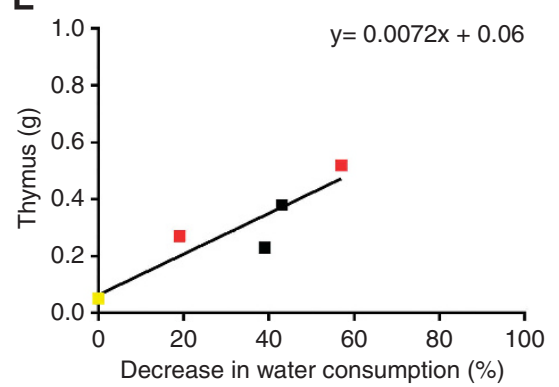

$\mathbf{F}$

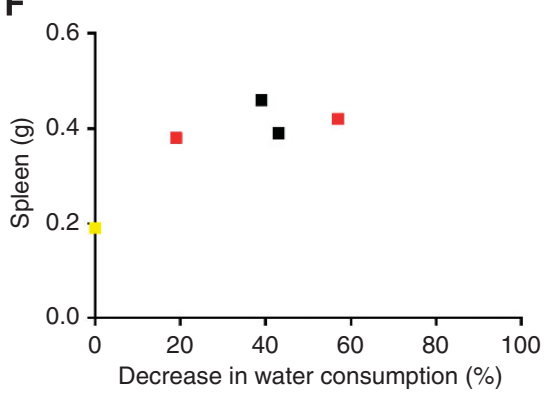

Figure 5. Relationship between food/water consumption and mean tumour burden. Tumour 1 in yellow, tumour 2 in red and tumour 3 in black. (A-C) Scatter plots to show relationships between decrease in food consumption and total weight of lymph nodes (cervical, brachial, inguinal, mesenteric), thymus and spleen. (D-F) Scatter plots to show relationships between decrease in water consumption and total post-mortem weight of lymphoid organs. 
disease progression in mice with lymphoma and could potentially be used more widely as a biomarker for mice with other cancers.

\section{ACKNOWLEDGEMENTS}

We thank Huw Thomas, Paul Flecknell and all members of the NDP laboratory for helpful advice. CAR is funded by a National Centre for the Replacement, Refinement and Reduction of Animals in Research David Sainsbury Fellowship (grant NC/K500513/1), $\mathrm{JEH}$ is funded by Leukaemia and Lymphoma Research (grant 11022) and JB is funded by the Wellcome Trust (grant 094409). Additional NDP lab funding was received from Cancer Research UK programme grant C1443/A12750.

\section{REFERENCES}

Bouwknecht JA, Olivier B (2007) The stress-induced hyperthermia paradigm as a physiological animal model for anxiety: A review of pharmacological and genetic studies in the mouse. Neurosci Biobehaviour Rev 31: 41-59.

Campbell KJ, Bath ML, Turner ML, Vandenberg CJ, Bouillet P, Metcalf D, Scott CL, Cory S (2010) Elevated Mcl-1 perturbs lymphopoiesis, promotes transformation of hematopoietic stem/progenitor cells, and enhances drug resistance. Blood 116(17): 3197-3207.

Edgar JL, Nicol CJ, Pugh CA, PauL ES (2013) Surface temperature changes in response to handling in domestic chickens. Physiol Behavior 119: 195-200.

Ferrao PT, Bukczynska EP, Johnstone RW, McArtur GA (2012) Efficacy of $\mathrm{CHK}$ inhibitors as single agents in MYC-driven lymphoma cells. Oncogene 31: 1661-1672.

Franco NH, Correla-Neves M, Olsson IAS (2012) How 'humane' is your endpoint?- refining the science-driven approach for termination of animal studies of chronic infection. PLoS Pathogens 8(1): e1002399.

Gaskill BN, Gordon CJ, Pajor EA, Lucas JR, Davis JK, Garner JP (2012) Heat or insulation: Behavioural titration of mouse preference for warmth or access to a nest. PLoS One 7(3): e32799.

Gaskill BN, Pritchett-Corning KR, Gordon CJ, Pajor EA, Lucas JR, Davis JK, Garner JP (2013a) Energy reallocation to breeding performance through improved nest building in laboratory mice. PLoS One 8(9): e74153.

Gaskill BN, Rohr SA, Pajor EA, Lucas JR, Garner JP (2011) Working with what you've got: Changes in thermal preference and behavior in mice with or without nesting material. J Thermal Biol 36(3): 193-199.

Gaskill BN, Winnicker C, Garner JP, Pritchett-Corning KR (2013b) The naked truth: breeding performance in nude mice with and without nesting material. App Anim Behav Sci 143(2-4): 110-116.

Harris AW, Pinkert CA, Crawford M, Langdon WY, Brinster RL, Adams JM (1988) The $\mathrm{E} \mu$-myc transgenic mouse. J Exp Med 167: 353-371.

Hawkins P (2002) Recognizing and assessing pain, suffering and distress in laboratory animals: a survey of current practice in the UK with recommendations. Laboratory Animals 36: 378-395.

Hess SE, Rohr S, Dufour BD, Gaskill BN, Pajor EA, Garner JP (2008) Home improvement: C57BL/6J mice given more naturalistic nesting materials build better nests. JAALAS 47(6): 25-31.

Jacobsen KR, Jørgensen P, Pipper CB, Steffensen AM, Hau J, Abelson KSP (2013) The utility of fecal corticosterone metabolites and animal welfare assessment protocols as predictive parameters of tumor development and animal welfare in a murine xenograft model. In vivo 27: 189-196.
Kelly PN, Grabow S, Delbridge ARD, Strasser A, Adams JM (2011)

Endogenous Bcl- $\mathrm{x}_{\mathrm{L}}$ is essesntial for Myc-driven lymphomagenesis in mice. Blood 118(24): 6380-6386.

Kilkenny C, Browne WJ, Cuthill IC, Emerson M, Altman DG (2010) Improving bioscience research reporting: the ARRIVE guidelines for reporting animal research. PLoS Biol 8(6): e1000412.

Kokolus KM, Capitano ML, Lee C-T, JW-L Eng, Waight JD, Hylander BL, Sexton S, Hong CC, Gordon CJ, Abrams SI, Repasky EA (2013) Baseline tumor growth and immune control in laboratory mice are significantly influenced by subthermoneutral housing temperature. PNAS 110(50): 20176-20181.

Lindsay T, Jonas B, Sevcik M, Kubota K, Halvorson K, Ghilardi J et al. (2005) Pancreatic cancer pain and its correlation with changes with tumor vasulature, macrophage infiltration, neuronal innervation, body weight and disease progression. Pain 119: 233-246.

Mason KD, Vandenberg CJ, Scott CL, Wei AH, Cory S, Huang DCS, Roberts AW (2008) In vivo efficacy of the Bcl-2 antagonist ABT-737 against aggressive Myc-driven lymphomas. PNAS 105(46): 17961-17966.

NC3Rs (2013) Humane end points: National Centre for the Replacement, Refinement and Reduction of Animals in Research. http://www.nc3rs.org.uk/category.asp?catID=21 (accessed:08/12/2013).

Paster EV, Villines KA, Hickman DL (2009) Endpoints for mouse abdominal tumor models: refinement of current criteria. Comp Med 48(3): 234-241.

Ray MA, Johnston NA, Verhulst S, Trammell RA, Toth LA (2010) Identification of markers for imminent death in mice used in longevity and aging research. J Am Assoc Lab Anim Sci 49(3): 282-288.

Roughan JV, Flecknell PA, Davies BR (2004) Behavioural assessment of the effects of tumour growth in rats and the influence of the analgesics carprofen and meloxicam. Laboratory Animals 38(3): 286-296.

Russell WMS, Burch RL (1959) The Principles of Humane Experimental Technique. Methuen: London.

Van Bogaert MJV, Groenink L, Oosting RS, Westphal KGC, van der Gugten J, Olivier B (2006) Mouse strain differences in autonomic responses to stress. Genes Brain Behavior 5: 139-149.

van Loo PLP, Everse LA, Bernsen MR, Baumans V, Hellebrekers LJ, Kruitwagon CLJJ, den Otter W (1997) Analgesics in mice used in cancer research: reduction of discomfort? Laboratory Animals 31: 318-325.

Wall M, Poortinga G, Stanley KL, Lindemann RK, Bots M, Chan CJ, Bywater MJ, Kinross KM, Astle MV, Waldeck K, Hannan KM, Shortt J, Smyth MJ, Lowe SW, Hannan RD, Pearson RB, Johnstone RW, McArthur GA (2013) The mTORC1 inhibitor everolimus prevents and treats $\mathrm{E} \mu-M y c$ lymphoma by restoring oncogene-induced senescence. Cancer Discovery 3(81): 82-95.

Warn PA, Brampton MW, Sharp A, Morrissey G, Steel N, Denning DW, Priest T (2003) Infrared body temperature measurement of mice as an early predictor of death in experimental fungal infections. Laboratory Animals 37(2): 126-131.

Wong D, Makowska IJ, Weary DM (2013) Rat aversion to isoflurane versus carbon dioxide. Bio Lett 9(1): 20121000.

Workman P, Aboagye EO, Balkwill F, Balmain A, Bruder G, Chaplin DJ, Double JA, Everitt J, Farningham DA, Glennie MJ, Kelland LR, Robinson V, Stratford IJ, Tozer GM, Watson S, Wedge SR, Eccles SA. Committee of the National Cancer Research Institute (2010) Guidelines for the welfare and use of animals in cancer research. Br J Cancer 102: 1555-1577.

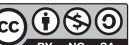

This work is licensed under the Creative Commons Attribution-NonCommercial-Share Alike 3.0 Unported License. To view a copy of this license, visit http://creativecommons. org/licenses/by-nc-sa/3.0/ 